

RESEARCH ARTICLE

\title{
EVALUATION OF IMPLEMENTATION PROGRAM OF SCHOOL EDUCATION BASELINE TECHNIQUES TNI AIR FORCE
}

\author{
Khaerudin, Mukhneri Mukhtar and R. Madhakomala \\ Doctoral Program of Educational Management, UniversitasNegeri Jakarta, Jakarta, Indonesia.
}

\section{Manuscript Info}

Manuscript History

Received: 26 July 2020

Final Accepted: 31 August 2020

Published: September 2020

Key words:-

Program, Evaluation, Interdisciplinary

Education, CIPP Evaluation Model

\section{Abstract}

Through education programs can produce professional Air Force personnel. One of the educational programs is the basic technical vocational school education program and since the education program was implemented in the education system. it has never been evaluated. The purpose of this study is to evaluate the Education Program evaluation. This research method is descriptive qualitative, using CIPP evaluation model which consist of the component of Context, Input, Process, and Product. The data collected were primary and secondary data obtained through interviews, observation and document studies. Data validation is done by triangulation. Furthermore, the data were analyzed to obtain the results of the study. The results of this study indicate that: 1) Context evaluation, obtained an excellent category score (89\%) 2) Input evaluation, obtaining excellent category score $(80 \%) 3$ ) Process evaluation, obtaining good category score (65\%) and 4) Product Evaluation, obtaining excellent category score (85\%). The overall evaluation showing the results of very an effective $(79,6 \%$ aspect is considered very good), it means an effective education program to achieve the goal of increasing the competence of personel of aircraft maintenance engineering techniques that will be implemented in the work environment. Thus, feasible to be continued and developed.

Copy Right, IJAR, 2020,. All rights reserved.

\section{Introduction:-}

The national defense system in the face of military threats, places the Indonesian National Army (TNI) as the main component supported by reserve components and supporting components. The Air Force has the main task of carrying out, maintaining and securing the territorial sovereignty of the Republic of Indonesia in the air, as well as participating in the success of national development in the context of achieving national goals. By looking at their duties and roles in nation-building, the Air Force is always required to improve capability and preparedness in carrying out every form of assignment, both in the form of military operations and military operations other than war. In carrying out this task, it is necessary to have a competent and professional Air Angktan TNI soldier.

To have a professional Air Force soldier the steps taken are through education. This education sector can improve the ability of every personnel, especially the sergeant, who are in charge of caring for air defense equipment, especially airplanes, to be able to carry out the main tasks of the Air Force organization. 
In accordance with the opinion of Kaufman and Fenwick W. English cited by SuharsimiArikunto, emphasizing the need for an analysis of needs in solving educational problems (Suharsimi \& Jaba, 2014). By analyzing the education needs of non-commissioned personnel in aircraft maintenance techniques, several problems that must be resolved soon are: (1) the number of non-commissioned personnel in the near future will retire; (2) purchase of the main weapons system equipment, especially modern aircraft from the western countries; (3) a developing education system; (4) changes in the Organization of the Air Force; (5) lack of skilled workers in maintaining airplanes. The Air Force applied an educational model in the development of the Indonesian Air Force's education system using the instructional system development (ISD) model (Navedtra, 1975).

To meet skilled technical officer personnel, the effort that can be made is through the education program in the same manner as the results. The education program aims to provide knowledge, skills and attitudes and attitudes to the Air Force Bintara in the field of aircraft maintenance techniques. Evaluation of the basic technical vocational school education program needs to be done since since it was implemented in the Indonesian Air Force's education system, there has never been a comprehensive and comprehensive evaluation.

Evaluation also helps in planning, developing, implementing, improving and continuing an activity. In every educational activity there must be an evaluation of the implementation of activities, with the aim of knowing whether the activity is in accordance with the objectives set in the educational activity. According to his opinion Prof. Dr. AtwiSuparman, M.Sc, that evaluation is a necessity and is absolutely necessary in an education system (Suparman, 1999). Stufflebeam \& Shrinkfield, (1987)said that " Evaluations most important purpose is not to prove but to improve".

Program evaluation can be used for various purposes, especially in making decisions Stufflebeam and Zhang said that: Program evaluation is the assessment of a programs value. Specifically, a program evaluation is the systematic process of delineating, obtaining, reporting, and applying descriptive and judgmental information about a programs quality, cost effectiveness, feasibility, safety, legality, sustainability, transferability, fairness, importance, and the like (Shrinkfield, Madaus, \& Kellaghan, 2002, Shrinkfield, 2007)

The evaluation model used in the evaluation study of the implementation of the Air Force's basic technical vocational school education, the Context, Input, Process, Product (CIPP) Evaluation Model, developed by Stufflebeam and Shikfield, explained:The Thrust of CIPP evaluations is to provide sound information that will help service providers regularly assess and improve services and make effective and efficient use of resources, time and technology in order to serve the well-being and targeted needs of rightful beneficiaries appropriately and equitably(Shrinkfield et al., 2002).

This CIPP model will be used as a reference in evaluating the implementation of the Air Force's basic technical vocational school education program. Education Skadron 302 (Skadik 302) which organizes basic technical vocational school education programs of the Air Force has carried out routinely every year until now, but until now there has never been a comprehensive program evaluation, so that the effectiveness of the program has not been known certainly. The aim is to assess program achievement, planning, implementation and the influence of the program on changes in the evaluated object, as well as finding obstacles that occur, so that strategies can be formulated for further program improvement.

Based on the background of the problem described above, the focus of this research can be formulated as follows: 1 . Evaluation of educational programs as far as the aspects of the context aspects consist of: a. vision and mission of the education program; $b$. educational program objectives; $c$. target of the education program.2. Evaluation of educational programs as far as the aspects of the input aspect consist of: a. education program strategy; $b$. educational program design; c. education program plan for the same amount; d. readiness of resources (Instructors and Students).3. Evaluation of educational programs as far as the aspects of the implementation aspects or (process aspects) consist of: a. implementation of learning programs, b. implementation of learning activities.4. Evaluation of educational programs as much as the results of the implementation or (product aspects) consisting of: a. learning outcomes of achieving knowledge mastery competencies; $b$. learning outcomes of achievement of mastery competency (skill); c. learning outcomes attain mastery or behavior competency.

\section{Method:-}

The focus of this research is an evaluation of the Air Force's basic technical vocational school education program in the Wingdiktekkal. The research method used was descriptive qualitative, using the CIPP evaluation model. According to Stufflebeam, which consists of Context, Input, Process, and Product. Program evaluation of the CIPP 
model (context, input, process, product), views a program that is evaluated as a system, so that in carrying out the evaluation, it must be based on its components. Thus, evaluation of input components must be preceded by context evaluation, process evaluation must be preceded by evaluation of input, evaluation of results must be preceded by evaluation of the process. So that this evaluation is linear, which requires evaluations to be carried out sequentially, starting from evaluating the context components, input components, process components, outcome components.

The data collected is primary data and secondary data obtained through interviews, observation and documents study. Data from each aspect evaluated were compared with evaluation criteria, then analyzed to obtain the findings of the research. According to Miles and Huberman, qualitative data analysis activities are carried out through data collection activities, data reduction, data presentation, and data verification(Sugiyono, 2017). The instrument is said to have high validity if the tool performs the function of the measuring instrument.

The data validation of this research was carried out by triangulating data sources and techniques. The data collected is compared with evaluation criteria, assessed and interpreted using assessment guidelines which consist of four categories, namely: lacking, sufficient, good, excellent. Based on the research findings carried out in the discussion, then conclusions were drawn describing the level of effectiveness of the program and recommendations as input for the best policy on the sustainability of the education program of Air Force's basic technical vocational school education in the WingdiktekkalKalijatiSubang.

\section{Results And Discussion:-}

The results and discussion of the evaluation of the education program in the Wingdiktekkalare as follows:

\section{Evaluate Context.}

Program vision and mission. The formulation of the Education Program's Vision and Mission of the basic technical vocational school has considered the needs of the Air Force's organization, for that of the educational needs that have been described in the formulation of the vision and mission of the basic technical vocational school education program. The vision should emphasize purpose, behavior, performance criteria, decision rules, and standards that serve the public and create public value... (Bryson 2011: 273). The vision must emphasize goals, behaviors, performance criteria, decision rules, and standards that serve the public and create value and must be specific and reasonable. From theory about vision and analyzing program vision, it can be produced that the vision of the basic technical vocational school education program in accordance with the criteria that it contains purpose and values that will form the basis of long-term success and mission is activities to achieve the vision of the program. Educational needs that are the objectives of the program have been described in the formulation of the program's vision and mission. The socialization of the program's vision and mission of the basic technical vocational school has been carried out and received a positive response from stakeholders, but the forms of activities that carried out have not been comprehensive and programmed. The findings of the program evaluation on the vision and mission of education are considered "very good".

Program Objectives. Formulation of objectives based on educational needs. Education will be implemented only really needed for the achievement of educational needs in the field. The results of the needs analysis of tasks and work in the field are further elaborated into the type of education needed, the number and composition of personnel to be educated, when and where education will be carried out. Criteria for formulating program objectives are related to program objectives, after analysis, get the results that the program objectives are appropriate The formulation of program objectives is based on needs, educational problems, and the development of educational goals, and based on legal aspects in formulating program objectives. The purpose of the program has been well organized according to the rules of formulation of educational goals developed containing cognitive, effective, and psychomotor goals. The findings of the program evaluation on the objectives of the education program were considered "very good".

Educational Objectives. The formulation of the objectives of the basic technical vocational school education program based on educational needs, clearly and detailedly described in the program activities, can be operationalized in accordance with the vision and mission and educational objectives, which is the result of data analysis from interviews and observations and with evaluation criteria. The findings of the program evaluation on the education targets are considered "very good". Which means that most have met the standard criteria that have been determined. From the results of the context evaluation described above, it shows that most indicators (aspects evaluated) meet the evaluation criteria. 
Thus, the findings of the context evaluation results are considered "very good" with a percentage assessment of $86 \%$.

\section{Evaluation of Program Input (Input Evaluation).}

Program Strategy. That the results of the analysis of the data obtained produce that in formulating a strategy has been adjusted to the objectives set, because the strategy includes ways to achieve goals and instructors who will teach must be competent and professional, and students are enthusiastic and highly motivated who are supported by equipment, facilities and infrastructure, and adequate budget. That the formulation of the basic technical vocational school education program strategy in part of the project has fulfilled in accordance with the evaluation criteria and needs to be supported by good and complete educational facilities and infrastructure to achieve success in achieving educational goals. The findings of the program evaluation on the education program strategy are considered "very good".

Educational Design Program. That the results of the analysis of the data obtained produce that The education program of the basic technical vocational school already has a program design that is in accordance with the target needs of the education program. The implementation is translated into activities in several stages. The design of the education curriculum program already in accordance with the educational model that has been developed by the Air Force, namely the ISD (Instructional System Development) model which is characterized by system. The findings of the program evaluation on the design of educational programs are considered "very good".

Educational Program Plan. The education program plan consists of: educational curriculum readiness, structure of learning material, syllabus and learning program unit (SAP), guidance and nurturing program, educational calendar of the basic technical vocational school, weekly schedule, monitoring and evaluation. The results of the evaluation show that: (a) the readiness of the education curriculum has been arranged well and validly, (b) the structure of the learning material has been described in detail and sequentially, the allocation of study hours according to the material weight and learning objectives, (c) syllabus and learning program unit (SAP) have been well structured but incomplete, (d) guidance and nurturing programs have been arranged in full, (e) education calendar of the basic technical vocational school already in accordance with the educational plan, (f) schedule weekly has been well prepared, (g) monitoring and evaluation have not been well organized. After analyzing the data obtained it is faced with evaluation criteria, The findings of the program evaluation on the education program plan are considered "very good".

Resource Readiness. Based on the data obtained, it is continued by analyzing the readiness of resources to produce that (a) the readiness of the instructor already has competence and qualifications, but the teaching ability has not yet partially participated in military teacher education (b) the number of education personnel has been fulfilled, but competencies need to be improved (c) student readiness has met administrative and academic requirements, (d) readiness of the student handbook is sufficient in number, but it needs to be improved (e) readiness of facilities and infrastructure (classrooms, workshops, libraries, dormitories, facilities of transportation), mostly it has been fulfilled, but it needs to be improved in managing the library and updating the reference books, (f) the education budget supported from the APBN budget in accordance with the well-planned financing provisions, but there are still several activity plans that have not been supported as needed.

Overall the results of evaluation of input get a very good category with an $80 \%$ percentage evaluation, which means that most program inputs are in accordance with or meet the criteria that have been set.

1. Evaluation of Program Implementation (Process Evaluation).

a. Implementation of Learning Programs.

Implementation of Education Curriculum. Based on the data obtained and continued by analyzing against The education curriculum of the basic technical vocational school for the 2014 academic year was ratified by the Decree of the Head of the Air Force Staff Number: Kep / 195 / III / 2014 which has been implemented well and consistently, the curriculum is still valid and relevant to the needs of the organization.

Implementation of the Learning Material Structure. Based on the data obtained and continued by analyzing against The implementation of the structure of the learning material has been prepared according to the phasing of subject matter based on the learning psychology approach, ranging from easy to deep or difficult, the structure of the learning material has been structured systematically, and the structure of the learning material has been fully documented so as to facilitate the implementation of teaching. 
Implementation of Teaching Program: Syllabus and SAP. Based on the data obtained and continued by analyzing against Implementation of the teaching program: Syllabus and SAP, some instructors have already made a learning program unit (SAP), but there are some who do not understand the preparation of SAP, so the implementation of learning is less effective.

Implementation of the Guidance and Nurturing Program. Based on the data obtained and continued by analyzing against The implementation of guidance and nurturing program activities has been carried out with guidance and nurturing methods and techniques that have been well implemented, and consistent with the plans that have been made. Guidance and nurturing aims to help students in order to optimize their learning outcomes and to help students to solve problems or difficulties in learning.

Implementation of the Education Calendar. Based on the data obtained and continued by analyzing against The implementation of the educational calendar that has been carried out consistently, shows that learning activities can run in the most orderly manner, smoothly according to the program plan.

Implementation of the Weekly Schedule. Based on the data obtained and continued by analyzing against The implementation of the weekly schedule has been well implemented, but there are still some teaching activities that need to be rescheduled to synchronize with the activities of non-organic instructors who cannot meet the teaching schedule that has been prepared. This is due to the limited number of instructors who are competent in their fields.

Monitoring and Evaluation. Based on the data obtained and continued by analyzing against Monitoring and evaluation has been carried out by monitoring and evaluation but has not been consistent and implemented incidentally; monitoring and evaluation activities have been carried out internally; and the results of monitoring and evaluation activities have not been well documented and have not been consistent. The findings of the evaluation of the implementation of the learning program are considered "very good".

\section{Implementation of Learning Activities.}

Implementation of Student Learning Activities. Based on the data obtained and continued by analyzing against Learning activities carried out by students in the library are not optimal. Student participation in good learning and high motivation and responsibility in carrying out learning are considered good. Facilities and infrastructure can support the implementation of learning.

Implementation of Instructor Teaching Activities. Based on the data obtained and continued by analyzing against Instructor teaching activities are carried out according to a predetermined schedule, and on time with subject matter that fits the needs of students and is supported by adequate facilities and infrastructure but needs to be updated.

Implementation of Education Management Activities for Managers. Based on the data obtained and continued by analyzing against The implementation of the basic technical vocational school management activities, the data / information is obtained that the discipline of education managers is considered good; the motivation of the education managers in carrying out the task of carrying out the basic technical vocational school educational programs are considered good and the attitudes and behavior of the education managers are considered good.

Budget Implementation.Based on the data obtained and continued by analyzing against Implementation of budget support often faces problems, especially when budget disbursement is often late. (b) The management of the budget has been carried out in accordance with the provisions of the transparent and accountable APBN budget management, with supervision carried out from the internal and external of the Air Force. The findings of the evaluation of the implementation of learning activities are considered "very good".

Overall, the results of the evaluation of program implementation meet the criteria with a very good category with a percentage of $78 \%$, meaning that the majority of the basic technical vocational school program implementation had already meets the criteria or standards that have been set.

2. Evaluation of Program Results (Product Evaluation)

a. Program Outcomes.

Learning Outcomes Achievement of Knowledge Mastery Competencies. Based on the data obtained, it was continued by analyzing that Learning outcomes for mastery of knowledge value of $\geq 80$ average, so that this 
objective of the program and managed to achieve knowledge mastery competencies. The learning outcomes are in accordance with the expected goals as a provision for students to carry out aircraft maintenance work in the Air Force air squadron. The average achievement of knowledge is the competency mastery of educational students is in number A-41/2014; A-42//2015 and A-43/2016 are 89.77 which means it has exceeded established criteria and shows that the set of learning objectives can be achieved. Thus, the learning outcomes of achieving mastery competency in education knowledge are considered very good.

Learning Outcomes Achievement of Skill Mastery Competencie. Based on the data obtained, it was continued by analyzing that The mastery of skills is one of the important factors of the education programs that is intended to improve skills in carrying out tasks in aircraft maintenance. Achievement of an average score skill of $\geq 80$ and this is an educational program objectives that apply the ISD method of assessment where Go and No Go are assessed. The average achievement mastery skills competency of education students as 41/2014; A-42//2015 and A-43/2016 are 85.20. It can be concluded that learning outcomes from attaining competency in mastering skills in education are mostly fulfilling in accordance with existing criteria. Thus, the learning outcomes of achieving mastery competencies in education skills are considered very good.

Learning Outcomes Achievement of Personality Mastery and Physical Compatibility Competencies. Based on the data obtained, it was continued by analyzing that Achievement of mastery of personality and physical fitness competencies which include: attitude to cooperate with related parties, attitude to be responsible for each task; and having good physical fitness is very much needed in carrying out the duties of maintaining aircraft of the Air Force. The learning outcomes of educational students as much as in the achievement of mastery of personality and physical fitness competencies, are in accordance with the objectives of the program has succeeded in achieving mastery competencies in attitudes and behaviors (personality) and physical fitness according to predetermined standards. The average achievement of mastery of attitudes and behaviors of education students in the same grade as A-41/2014; A42//2015 and A-43/2016 are for personality 82.39 and for physical adaptation 70.76. Success criteria for evaluating learning outcomes on indicators of attitudes and behavioral competency mastery (personality and physical fitness) with an average value for personality $\geq 75$ and for physical fitness $\geq 80$. It can be concluded that the learning outcomes of attaining educational competency skills are in part large or all fulfill in accordance with existing criteria. Thus, the learning outcomes of attaining competence in mastering personality and educational physical fitness in the same way are considered very good.

Use of Alumni for Institutions / User Agencies. Education as intended in order to produce non-commissioned personnel technicians for the maintenance of air force aircraft that are ready to use or work in a technical squadron or an air squadron maintenance aircraft. Therefore, the usefulness of alumni in the institution / user institution is being able to implement knowledge, skills and attitudes as an engineer in aircraft maintenance techniques. Alumni in implementing their capabilities in maintaining airplanes at the user's institution received a positive response, because the alumni were able to work in the fields studied, namely aircraft maintenance received a positive appreciation from the leadership of the institution / user institution. The criteria for the success of evaluating the results of the program achievements, on the indicators of the usefulness of alumni for institutions / user institutions are the usefulness of alumni in implementing tasks as aircraft maintenance technicians in user agencies / institutions, and positive responses / responses from user agencies. Thus, the findings of the program evaluation results are considered "very good" with a percentage rating of $85 \%$.

The results of the program evaluation (Product Evaluation) on the implementation of the education program in the Skadik 302 Wingdiktekkal with excellent categories mean that most program results meet the established criteria.

Based on the results of the evaluation of the implementation of the educational program in the Skadik 301 Wingdiktekkal with the CIPP Evaluation Model described above, a recapitulation was made with the overall research findings / results (Context, Input, Process, and Products) with the assessment of "Very Good" with a percentage assessment of $79.6 \%$, it means that most or all of the program implementation activities have met the evaluation criteria.

\section{Conclusion:-}

Based on the findings of the research and discussion results, it can be concluded as follows:

Evaluate the context of the program as follows: evaluation of the context of the program as the basis of the need to organize an education program like the Indonesian Air Force with a "very good" assessment (89\%), which is based on the need to improve the quality of human resources, especially technical assistance for Air Force aircraf in order 
to have competency in aircraft maintenance, so that they are able to carry out aircraft maintenance tasks. The educational needs have been formulated into the vision, mission, and program objectives and targets of the education program.

Program input evaluation: program input includes program planning and preparation. In general, in preparing program strategies, program design, making education program plans and preparing program resources, which are components of program inputs with "excellent" assessment $(80 \%)$, they have been guided and implemented on the vision, mission of the program and program objectives and targets of educational programs that have been set.

Evaluate the implementation of the program: the implementation of educational programs and educational activities of the basic technical vocational school of the Air Force has been carried out with a "good" (65\%) assessment in accordance with the plans and criteria / standards that have been made.

Evaluation of program results: is the result of an activity process aimed at meeting needs that are the basis of program implementation, program planning and preparation, and program implementation to achieve the goal of improving the quality of the sergeant technical that have aircraft maintenance competence. The results of the basic technical vocational school education program have been achieved with an "excellent" rating $(85 \%)$.

Overall, the evaluation of the basic technical vocational school education program of the Air Force in Wingdiktekkal looks effective (79,6\% aspect is considered very good), in achieving educational goals in improving the competence of the sergeant technical in the maintenance of professional Air Force aircraft. Based on the conclusions above, it can be recommended that the basic technical vocational school education program in the Wingdiktekkal is feasible to be continued and developed, but its management needs to be corrected according to the needs in order to improve the quality education programs.

\section{References:-}

1. Navedtra. (1975). Interservice Procedures for Instructional System Development, Phase - I, Analyze.

2. Shrinkfield. (2007). Evaluation Theory, Models and Applycations. Jossy Bass.

3. Shrinkfield, Madaus, \& Kellaghan. (2002). Evaluation Models, Viewpoints on Educational and Human Service Evaluation. Bosto: Kluwer-Academic.

4. Stufflebeam, \& Shrinkfield, D. . (1987). The CIPP Model for Evaluation Program," Evaluation Models, Viewpoint on Educational Human Services Evaluation. Bostom: Kluwer-Nijhoff Publishing.

5. Sugiyono. (2017). Educational Research Methods, Quantitative, Qualitative and R \& D Approaches. Bandung: Alfabeta.

6. Suharsimi, A. S., \& Jaba, A. (2014). Educational Program Evaluation: Practical Guidelines for Students and Practitioners of Education. Jakarta: PT. Earth Literacy.

7. Suparman, A. (1999). Education And Exercise Program Evaluation. 